\title{
Current Biology \\ Feeding ecology has shaped the evolution of modern sharks
}

\section{Graphical abstract}

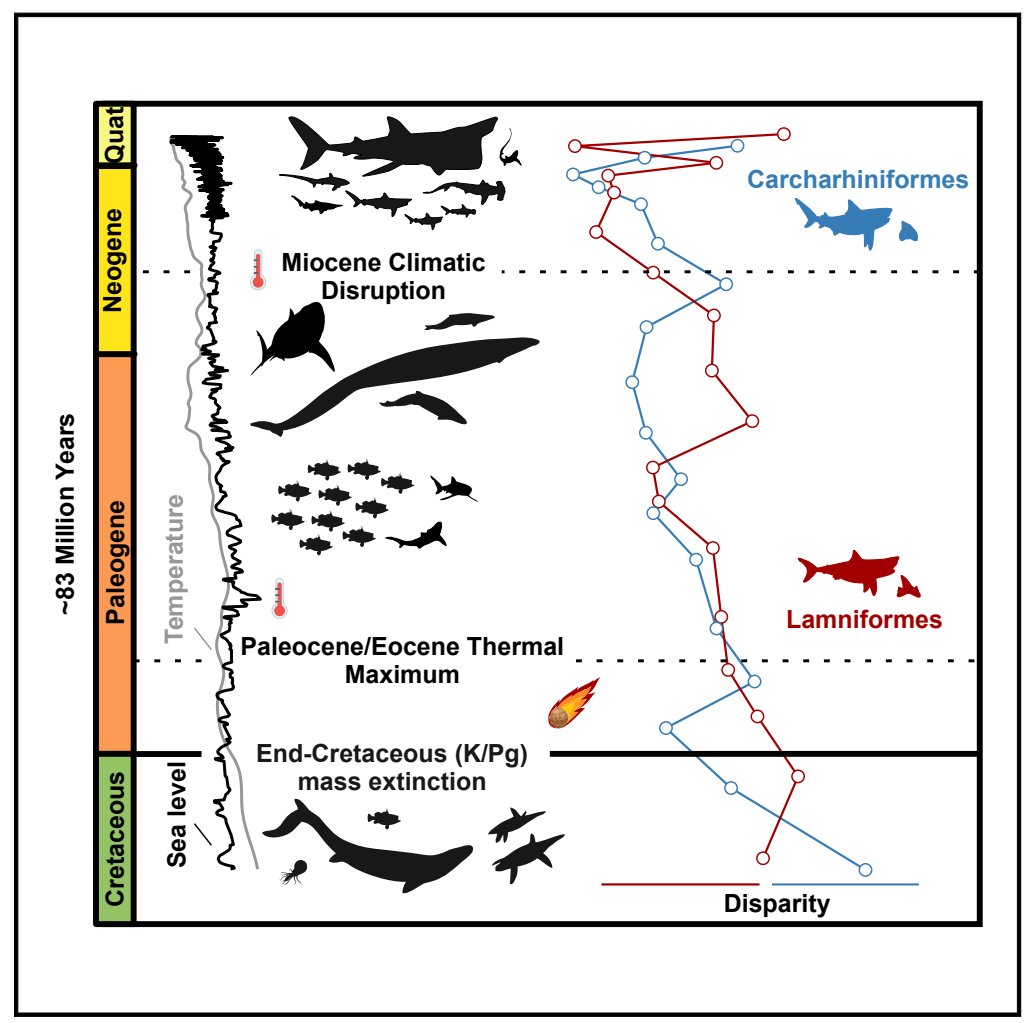

\section{Highlights}

- Shark tooth morphologies track changing habitats and resource availability

- Tooth shape correlates with diet in extant shark species

- Declines in lamniform disparity can be linked with dietary "specialization"

- Modern lamniforms are more disparate than coeval carcharhiniforms

\section{Authors}

Mohamad Bazzi, Nicolás E. Campione, Benjamin P. Kear, Catalina Pimiento, Per E. Ahlberg

\section{Correspondence}

mohamad.bazzi@uzh.ch

\section{In brief}

Bazzi et al. analyze the evolution of lamniform and carcharhiniform shark over the last $83 \mathrm{Ma}$. These closely related clades are shown to have undergone marked morphological segregation, with a combination of habitat change, prey availability, and feeding strategies influencing their community composition, diversity, and ecology over time. 
Feeding ecology has shaped the evolution of modern sharks

\author{
Mohamad Bazzi, ${ }^{1,2,7, *}$ Nicolás E. Campione, ${ }^{3}$ Benjamin P. Kear, ${ }^{4}$ Catalina Pimiento, ${ }^{2,5,6}$ and Per E. Ahlberg ${ }^{1}$ \\ ${ }^{1}$ Subdepartment of Evolution and Development, Department of Organismal Biology, Uppsala University, Norbyvägen 18A, 752 36 Uppsala, \\ Sweden \\ 2Paleontological Institute and Museum, University of Zurich, Zurich 8006, Switzerland \\ ${ }^{3}$ Palaeoscience Research Centre, School of Environmental and Rural Science, University of New England, Armidale, NSW 2351, Australia \\ ${ }^{4}$ Museum of Evolution, Uppsala University, Norbyvägen 16, 75236 Uppsala, Sweden \\ ${ }^{5}$ Department of Biosciences, Swansea University, Wallace Building, Singleton Park, Swansea SA2 8PP, UK \\ ${ }^{6}$ Smithsonian Tropical Research Institute, Box 2072, Balboa, Panama \\ ${ }^{7}$ Lead contact \\ *Correspondence: mohamad.bazzi@uzh.ch \\ https://doi.org/10.1016/j.cub.2021.09.028
}

\title{
SUMMARY
}

Sharks are iconic predators in today's oceans, yet their modern diversity has ancient origins. In particular, present hypotheses suggest that a combination of mass extinction, global climate change, and competition has regulated the community structure of dominant mackerel (Lamniformes) and ground (Carcharhiniformes) sharks over the last 66 million years. However, while these scenarios advocate an interplay of major abiotic and biotic events, the precise drivers remain obscure. Here, we focus on the role of feeding ecology using a geometric morphometric analysis of 3,837 fossil and extant shark teeth. Our results reveal that morphological segregation rather than competition has characterized lamniform and carcharhiniform evolution. Moreover, although lamniforms suffered a long-term disparity decline potentially linked to dietary "specialization," their recent disparity rivals that of "generalist" carcharhiniforms. We further confirm that low eustatic sea levels impacted lamniform disparity across the end-Cretaceous mass extinction. Adaptations to changing prey availability and the proliferation of coral reef habitats during the Paleogene also likely facilitated carcharhiniform dispersals and cladogenesis, underpinning their current taxonomic dominance. Ultimately, we posit that trophic partitioning and resource utilization shaped past shark ecology and represent critical determinants for their future species survivorship.

\section{INTRODUCTION}

Macroevolutionary studies aim to explain the drivers of largescale biological phenomena and often rely on fossils to elucidate the complex processes determining modern biodiversity. ${ }^{1-3}$ One frequently documented pattern is for closely related clades to manifest different radiation profiles over their extended geologic history. ${ }^{4-6}$ A notable example is the extreme asymmetry in species richness evident between modern lamniform and carcharhiniform sharks. These lineages are globally distributed in today's oceans but have starkly skewed diversities of 15 versus $>290$ living species, respectively. ${ }^{7}$ By contrast, the global fossil record shows that lamniforms were taxonomically more diverse than carcharhiniforms before the end-Cretaceous mass extinction, $66 \mathrm{Ma}^{8,9}$ The possible causes of this dramatic turnover include widespread oceanic cooling and intensified competition, which potentially promoted carcharhiniform diversifications during the Cenozoic. ${ }^{10}$ Conflictingly, though, assessments of dental disparity (morphological variability) suggest that trophic cascades and prey availability moderated the evolution of lamniforms and carcharhiniforms across the Mesozoic-Cenozoic transition. ${ }^{9}$

Sharks (Selachimorpha) are an optimal group for reconstructing macroevolutionary patterns because their dentitions are continuously replaced via a sequentially regenerative process termed polyphyodonty. ${ }^{11-13}$ The subsequent prolific production of shed teeth, which incorporate a decay-resistant dentine and enameloid composition, has resulted in an abundant and ubiquitous fossil record. ${ }^{14}$ To date, research on shark macroevolution has focused mainly on taxon counts and phylogenetic inferences to interpret diversity trends. $8,10,15,16$ Corresponding evaluations of dental disparity have also hitherto been limited in their geographic ${ }^{17}$ and chronostratigraphic $^{9}$ sampling.

Here, we undertake the first global-scale examination of lamniform and carcharhiniform dental disparity and morphology across the last $83 \mathrm{Ma}$. This time frame encompasses the Campanian-Maastrichtian ages preceding the Cretaceous/ Paleogene $(\mathrm{K} / \mathrm{Pg})$ mass extinction event and the entire Paleocene-Holocene interval leading up to the present day. We combine fossil and extant shark teeth to reconstruct deeptime patterns of evolution and evaluate the role of biotic and abiotic factors in driving diversity asymmetries between lamniforms and carcharhiniforms. With these data, we test the hypotheses that (1) sea level and temperature ${ }^{10}$ have functioned as major abiotic regulators of selachimorph evolution and (2) the covariation between tooth shape and diet, ${ }^{18,19}$ as extrapolated 
A

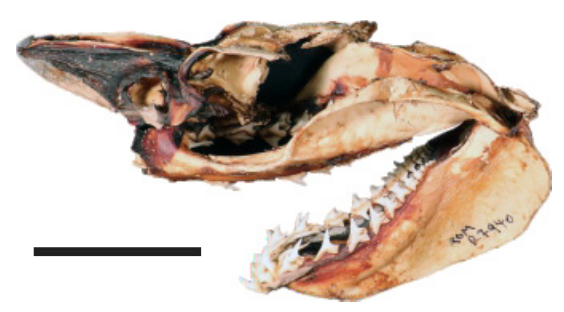

B

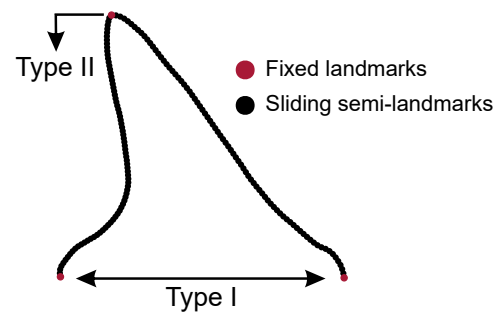

C
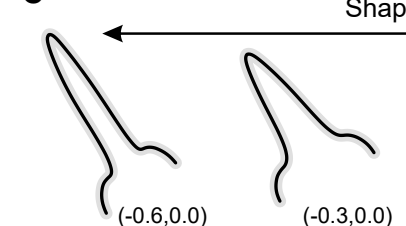

Shape spectrum along PC1

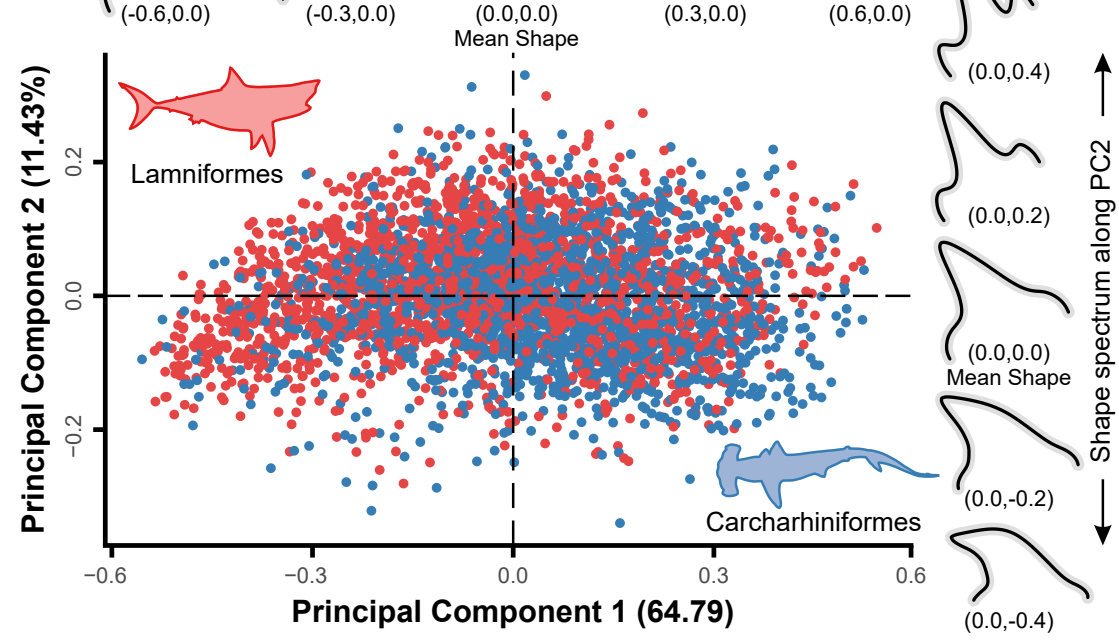

Figure 1. Geometric morphometric scheme and multivariate morphospace

(A and B) Landmark tooth-shape digitization illustrated using (A) an in situ dentition of the Shortfin mako, Isurus oxyrinchus (Royal Ontario Museum R7940; scale bar, $100 \mathrm{~mm}$ ) and (B) an upper lateroposterior tooth with fixed landmarks designating the apex and root-crown junction.

(C) 2D morphospace visualization of 3,837 individual lamniform (red: $n=1,924$ ) and carcharhiniform (blue: $\mathrm{n}=1,913)$ teeth on PC1 and PC2. Hypothetical morphologies are depicted as mathematically derived tooth outlines associated with equally distributed locations along each axis, as identified in the parentheses.

and S2B). PC1 (64.8\% of the total variance) describes a range from apicobasally tall and mesiodistally narrow to short and wide tooth morphologies (Figure 1C). PC2 $(11.43 \%)$ captures distally recurved teeth with reduced cusplets to upright and mesially angled teeth with prominent shoulders that bear denticles or cusplets. Lastly, PC3 (9.54\%) represents mesiodistally expanded and apically rounded teeth to mesiodistally tapered teeth incorporating well-developed lateral cusplets (Figure S2C). Lamniforms and carcharhiniforms share similar distributions across this morphospace but are statistically differentiated along PC1 and PC2 (Figure $1 \mathrm{C}$ ), although not on PC3 (Data S2A).

\section{Disparity dynamics}

Lamniform disparity was high throughout the Late Cretaceous and across the K/Pg in-

from living sharks, can be used to infer biotic mediators of past ecological change.

\section{RESULTS}

We compiled images of 3,837 extinct and extant shark teeth and converted them to a 2D landmark dataset for geometric morphometric analysis (Figures 1A, 1B, S1A, and S1B; Data S1). A Procrustes variance metric and a principal component analysis were used to estimate dental disparity and reconstruct morphological successions, respectively (STAR Methods). ${ }^{20,21}$ Additionally, we correlated tooth shape with published information on gut contents from living shark species ${ }^{22}$ to establish covariation between tooth shape and diet as a basis for inferring feeding ecology across our morphospace time series. Finally, to evaluate environmental correlates, ${ }^{23,24}$ a series of first-order autoregressive, AR(1), generalized least-squares (GLS) models compared disparity against sedimentary measures of sea-level and benthic oxygen isotope $\left(\delta^{18} \mathrm{O}\right)$ paleotemperature estimates.

\section{Dental morphospace}

Approximately $86 \%$ of the total variance in the dataset is explained by principal components (PC)1-PC3 (Figures 1C, S2A, terval (Figure 2A; Data S2B). However, a significant long-term decline commenced in the late Paleocene (Maastrichtian versus Thanetian: $\mathrm{p}_{R R P P}=0.041$ ) and persisted until the late Eocene (Priabonian). Lamniform disparity was seemingly high during the Oligocene and early Miocene. However, this peak diminished by the Rupelian once heterodonty was integrated into the disparity estimation model (Figure S3A; Data S2C-S2E). A significant disparity decrease (Figure 2A) from the late Oligocene-early Miocene (Aquitanian/Burdigalian) to the mid- to late Miocene and on into the early Pliocene (Zanclean) was similarly lost when diagnathic, but not monognathic, heterodonty was integrated (Data S2C-S2E).

Family-level partial disparity assessments (Figure S3B) specifically correlated low mid-Miocene (Langhian) disparity with lamnids and fotodontids (lineages including the white shark, Carcharodon carcharias, and "megatooth shark," Otodus megalodon, respectively). Late Pliocene (Piacenzian) lamniform disparity was otherwise comparatively high (Figure 2A; Data $\mathrm{S} 2 \mathrm{~B})$, despite the small sample size $\left(\mathrm{n}_{\text {Lamniformes }}=12\right)$, and peaked in the Holocene ( $n_{\text {Lamniformes }}=340$ ). Most conspicuously, Holocene lamniform disparity exceeds that of carcharhiniforms $\left(P V_{\text {Lamniformes }}=0.070 ; \mathrm{PV}_{\text {Carcharhiniformes }}=0.059 ; \mathrm{p}_{\mathrm{RRPP}}=0.004\right)$, even after "specialized" filter-feeding lamniforms were excluded $\left(P V_{\text {Lamniformes }}=0.067 ; \mathrm{PV}_{\text {Carcharhiniformes }}=0.059 ; \mathrm{p}_{\mathrm{RRPP}}=0.023\right)$. 


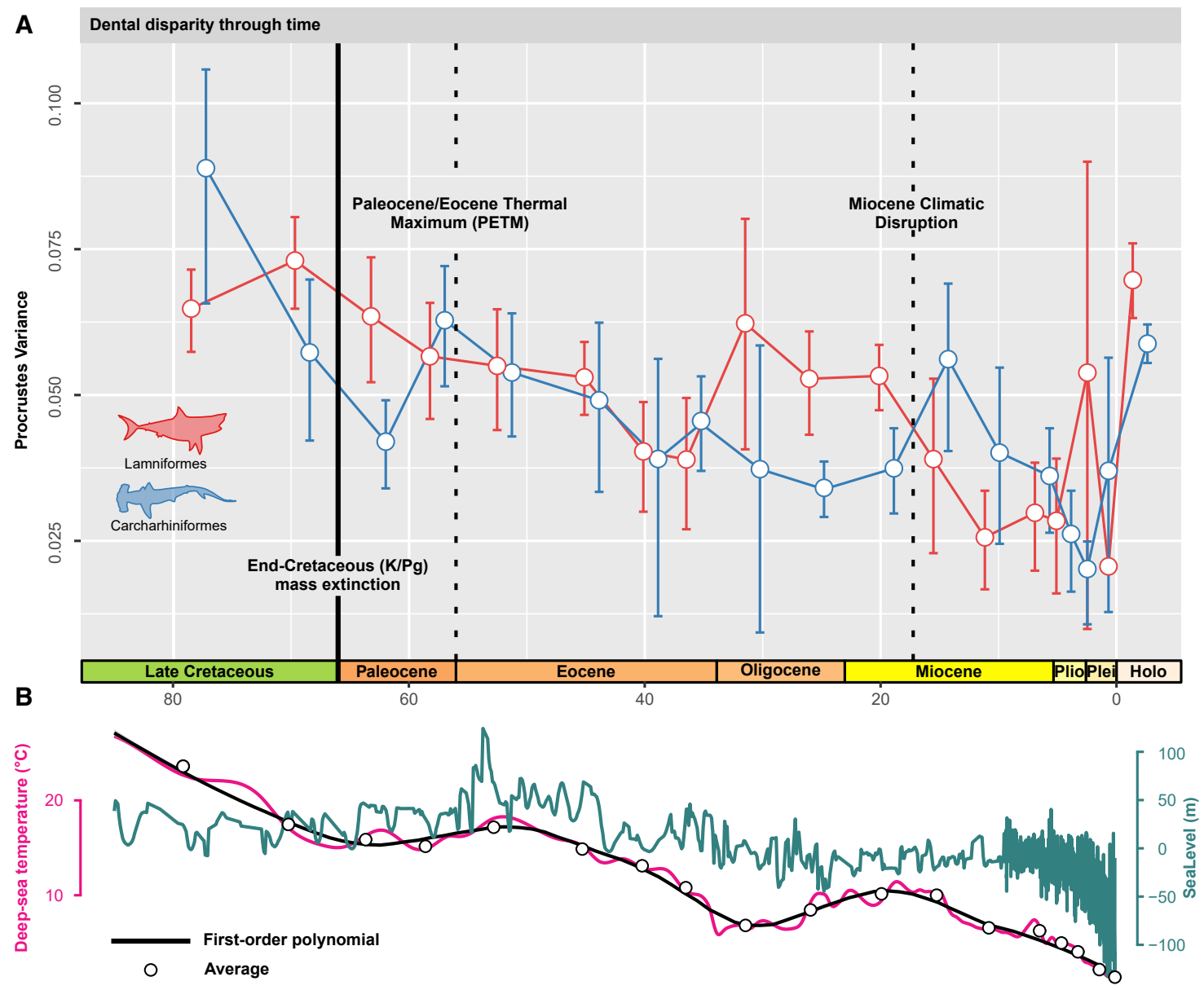

Age (Ma)

Figure 2. Dental disparity through time

(A) Comparative disparity of lamniforms (red) and carcharhiniforms (blue) with bootstrap (95\%) prediction intervals.

(B) Correlated sedimentary sea-level and $\delta^{18} \mathrm{O}$ paleotemperature (mid-age averages, open circles) curves fitted with a 0.3-span, first-order polynomial regression (loess).

See also Figure S3 for family-level partial disparity through time. Holo, Holocene; Plei, Pleistocene; Plio, Pliocene.

Carcharhiniform disparity peaked during the Late Cretaceous (Campanian), declined across the Campanian-Maastrichtian interval $\left(p_{R R P P}=0.04\right)$, and then remained largely static throughout most of the Cenozoic (Figure 2A; Data S2F). Langhian disparity estimates are notably high, though not significantly different from preceding or succeeding ages. Family-level partial disparities also showed that Paleocene triakids failed to recover their pre-K/Pg disparity levels, with carcharhinids becoming the principal contributors to carcharhiniform disparity by the early Eocene (Ypresian) - a pattern that continued to the Holocene (Figure S2C).

Generalized least-squares models revealed significant correlations between lamniform disparity and both global sea level and $\delta^{18} \mathrm{O}$ paleotemperature estimates (Figure 2B), with greater likelihood support than the intercept-only null models (Table 1). Notably, each $1 \mathrm{~m}$ sea level increase (Data S2G and S2H) corresponded to a 0.00025 increase in lamniform dental disparity $\left(p_{\mathrm{GLS}}=0.014\right)$. Carcharhiniform disparity was best explained by a temperature model, where each 1 degree increase in temperature correlates with a 0.0018 increase in dental disparity $\left(p_{\mathrm{GLS}}=0.002\right)$ but still with some sea-level interaction (Table 2; Data S2I and S2J).

Examination of the Cenozoic-only time bins using alternative environmental datasets $\left(n_{\text {Lamniformes }}=1,452 ; n_{\text {Carcharhiniformes }}=\right.$ 1,833; Data S2K and S2L) ${ }^{25,26}$ yielded more ambiguous results, with lamniform disparity best fitting the sea-level and null models, along with some support for the $\delta^{18} \mathrm{O}$ model (Data S2K). By contrast, Cenozoic-only carcharhiniform disparity was best explained by the sea-level model, with some support for both the $\delta^{18} \mathrm{O}$ and null models (Data S2L).

\section{Morphospace dynamics}

PC1 showed a shift toward taller, narrower teeth and the development of lateral cusplets among lamniforms across the $\mathrm{K} / \mathrm{Pg}$ boundary $\left(\mathrm{p}_{\mathrm{ANOVA}}=0.005\right.$; Figure $\left.3 \mathrm{~A}\right)$. Carcharhiniforms otherwise maintained their characteristically low-crowned, distally curved tooth morphologies, with a positive shift from the late Eocene to late Oligocene (Priabonian versus Chattian: 


\begin{tabular}{|c|c|c|c|c|c|c|c|c|}
\hline & Model & df & AIC & $\mathrm{BIC}$ & logLik & AlC.W & $\mathrm{AICc}$ & AlCc.W \\
\hline \multirow[t]{5}{*}{ Without $A R(1)$} & null & 2 & -95 & -94 & 50 & 0.0857 & -95 & 0.1478 \\
\hline & sea level & 3 & -98 & -96 & 52 & 0.3642 & -97 & 0.3975 \\
\hline & $\delta^{18} \mathrm{O}$ & 3 & -98 & -95 & 52 & 0.3198 & -96 & 0.3491 \\
\hline & sea level $+\delta^{18} O$ & 4 & -97 & -93 & 52 & 0.1672 & -94 & 0.0923 \\
\hline & sea level $\times \delta^{18} \mathrm{O}$ & 5 & -95 & -90 & 52 & 0.0631 & -90 & 0.0133 \\
\hline \multirow[t]{5}{*}{ With $A R(1)$} & null & 3 & -97 & -95 & 52 & 0.0424 & -95 & 0.0959 \\
\hline & sea level & 4 & -102 & -98 & 55 & 0.4054 & -99 & 0.4639 \\
\hline & $\delta^{18} \mathrm{O}$ & 4 & -101 & -98 & 55 & 0.3142 & -98 & 0.3596 \\
\hline & sea level $+\delta^{18} O$ & 5 & -100 & -95 & 55 & 0.1649 & -95 & 0.0721 \\
\hline & sea level $\times \delta^{18} \mathrm{O}$ & 6 & -98 & -93 & 55 & 0.0731 & -91 & 0.0086 \\
\hline
\end{tabular}

AIC, Akaike information criterion; AICc, AIC for small samples; AIC.W, AIC weights; AICc.W, AICc weights; BIC, Bayesian information criterion; df, degrees of freedom; logLik, log-likelihood.

$\mathrm{p}_{\text {ANOVA }}=0.032 ;$ Figure $\left.3 \mathrm{~A}\right)$. Lamniforms and carcharhiniforms then converged on PC1 by the Holocene (Figure 3A; Data S2M-S2V)

PC2 and PC3 illustrated a reduction in negative morphospace representing distally recurved and high-crowned triangular tooth morphologies among lamniforms across the $\mathrm{K} / \mathrm{Pg}$ interval but with some recovery by the mid-Eocene (Lutetian-Bartonian: Figures 3B and 3C; Data S2M, S2Q, and S2R). Carcharhiniforms otherwise remained largely stable but showed a significant negative shift $\left(p_{A N O V A}=0.008\right)$ at the Paleocene/Eocene boundary on PC2 (Figure 3B; Data S2U).

Lamniform morphospace redistributed along PC3 at the Oligocene/Miocene boundary. Initial average positive scores during the Aquitanian-Burdigalian became strongly negative by the Langhian and continued until the Holocene (Figure 3C; Data S2R). Negative scores along PC3 also coincided with a positive shift on PC1 (Figure 3A) and an overall decrease in lamniform disparity during the Miocene (Figure 2A; Data S2B).

\section{Dietary correlations}

A phylogenetic two-block partial least-squares (pPLS) covariance analysis supported a significant covariation between tooth shape and diet in extant lamniform and carcharhiniform species $\left(n_{\text {species }}=55 ; r_{P L S}=0.577 ; p=0.002 ; Z=3.023 ;\right.$ Figures 4 and S4). Lamniforms exhibited a high correlation coefficient $\left(\mathrm{n}_{\text {species }}=\right.$ 9; $r_{P L S}=0.862 ; p=0.073 ; Z=1.729$ ) yet did not reach statistical significance. The lamniform ecomorphological extremes along PLS1 (block 1) reflected a dichotomy of macrophagous vertebrate and cephalopod predators with pointed teeth versus microphagous zooplanktivores with bulbous conical teeth (Figures $4 \mathrm{C}$ and $4 \mathrm{D}$ ). Exclusion of specialized filter feeders produced comparable statistical results $\left(n_{\text {species }}=7 ; r_{P L S}=0.873 ; p=\right.$ $0.09 ; Z=1.382$ ) but with contrasting tooth shapes ranging from mesiodistally narrow, pointed teeth in piscivores to shorter, triangular teeth in cephalopod hunters (Figures S5A and S5B).

The shape-diet pPLS correlation coefficient for carcharhiniforms (Figures $4 \mathrm{E}$ and $4 \mathrm{~F}$ ) was lower but significant $\left(\mathrm{n}_{\text {species }}=\right.$ $46 ; r_{P L S}=0.584 ; p=0.002 ; Z=3.538$ ). PLS1 captured durophagy on decapod crustaceans versus predation on bony fish and other chondrichthyans (Figures 4E and 4F). Except for piscivorous and, to some extent, chondrichthyan-based diets, dietary loadings for carcharhiniforms on PLS1 contrasted with lamniforms (Figures 4C and $4 \mathrm{E}$ ), especially when lamniform filter feeders were removed (Figures S5A and S5B).

The ordinated dietary breadth (ODB) analysis ${ }^{27}$ of extant lamniforms and carcharhiniforms suggested that these groups utilize broadly similar prey breadths, with positively skewed ODB distributions indicating a general bias toward dietary specialization (Figures 5A and 5B). Phylogenetic ANOVA and Tukey's HSD tests failed to reject ODB uniformity between lamniforms and carcharhiniforms at order- or family-level groupings (Figure 5C; Data $\mathrm{S} 2 \mathrm{~W}$ ). Nevertheless, ODB distributions indicated a greater concentration of low ODB values in lamniforms (modal value $=0.1$ ), reflecting stronger biases toward dietary "specialization" - e.g., toward cephalopods in thresher sharks (Alopiidae), piscivory in the goblin shark (Mitsukurina owstoni), and zooplanktivory in the basking shark, Cetorhinus maximus. By comparison, carcharhiniforms tended toward higher ODB values (modal value $=0.25$; Figures $5 \mathrm{~A}$ and $5 \mathrm{~B}$ ), with notable examples including the tiger shark (Galeocerdo cuvier) and blue shark (Prionace glauca), which utilized all but one of the dietary categories designated here.

Significant ODB associations were also found on PC2 (Pearson's product-moment correlation: $r=0.402 ; p=0.001$; Figures S5C and S5D). This correlated "generalist" diets (high ODB values) with upright, mesiodistally narrow teeth flanked by prominent cusplets (positive PC2 scores) versus specialist diets with distally recurved teeth flanked by reduced cusplets. Finally, we detected no association between ODBs and intraspecific disparity in either lamniforms or carcharhiniforms (Figures S4E-S4G) or with monognathic heterodonty in lamniforms as estimated from a subset of complete tooth rows representing 10 species (Data S2X).

\section{DISCUSSION}

Our results demonstrate that (1) lamniforms and carcharhiniforms maintained comparable levels of disparity during the Late Cretaceous despite lamniform taxic dominance; (2) these clades morphologically diverged after the K/Pg boundary; (3) carcharhiniform disparity has been largely stable since the Mesozoic, but with some family-level increases in the early Eocene; (4) lamniform disparity declined during the midMiocene-early Pliocene; (5) lamniforms exhibited high disparity 


\begin{tabular}{|c|c|c|c|c|c|c|c|c|}
\hline & Model & $d f$ & $\mathrm{AIC}$ & $\mathrm{BIC}$ & logLik & AIC.W & $\mathrm{AlCc}$ & AlCc.W \\
\hline \multirow[t]{5}{*}{ Without $A R(1)$} & null & 2 & -95 & -94 & 50 & 0.0060 & -95 & 0.0119 \\
\hline & sea level & 3 & -99 & -97 & 53 & 0.0441 & -98 & 0.0558 \\
\hline & $\delta^{18} \mathrm{O}$ & 3 & -105 & -102 & 55 & 0.5974 & -103 & 0.7567 \\
\hline & sea level $+\delta^{18} \mathrm{O}$ & 4 & -103 & -99 & 55 & 0.2252 & -100 & 0.1443 \\
\hline & sea level $\times \delta^{18} \mathrm{O}$ & 5 & -102 & -97 & 56 & 0.1274 & -97 & 0.0312 \\
\hline \multirow[t]{5}{*}{ With $A R(1)$} & null & 3 & -96 & -94 & 51 & 0.0174 & -95 & 0.0432 \\
\hline & sea level & 4 & -99 & -96 & 54 & 0.0716 & -96 & 0.0898 \\
\hline & $\delta^{18} \mathrm{O}$ & 4 & -103 & -100 & 56 & 0.5970 & -100 & 0.7490 \\
\hline & sea level $+\delta^{18} \mathrm{O}$ & 5 & -101 & -97 & 56 & 0.2211 & -96 & 0.1061 \\
\hline & sea level $\times \delta^{18} \mathrm{O}$ & 6 & -100 & -94 & 56 & 0.0929 & -92 & 0.0119 \\
\hline
\end{tabular}

during the late-Pliocene-Holocene; and (6) lamniform disparity currently exceeds that of carcharhiniforms despite their contrasting taxonomic richness (Figure 2A).

Despite static lamniform disparity across the K/Pg boundary, GLS model-fitting confirms that their decline throughout the Cenozoic can be linked to global sea-level and temperature ${ }^{10}$ reductions initiated across the $\mathrm{K} / \mathrm{Pg}$ boundary (Data S2G and $\mathrm{S} 2 \mathrm{H})$. Specifically, the depletion of lamniform species diversity and a shift toward more "generalized" diets characterized by mesiodistally narrow tooth morphologies coincides with widespread epicontinental regression (e.g., the Western Interior Seaway of North America). ${ }^{28}$ Smaller-bodied lamniforms were especially dominant in these epeiric settings ${ }^{29}$ and thus may have been disproportionately impacted by latest Cretaceous eustatic change. ${ }^{9,30}$

Alternatively, the morphological divergence of lamniforms and carcharhiniforms (Figure $3 \mathrm{~A}$ ) does not support ecological competition as a regulator of their Cenozoic evolution. ${ }^{10}$ Indeed, such community interactions are difficult to discern from the time-averaged fossil record. ${ }^{31-34}$ Moreover, while some lamniforms and carcharhiniforms of equivalent body size do co-occur in modern habitats (e.g., C. carcharias with Carcharhinus brachyurus, Isurus oxyrinchus with many carcharhiniform species, and Isurus paucus with Carcharhinus longimanus), ${ }^{7,35}$ most exhibit ecological differentiation into predominantly pelagic versus neritic environments. ${ }^{7,36}$ Combined with our discovery of Cenozoic ecomorphological divergence (Figures $3 \mathrm{~A}$ and $4 \mathrm{~B}$ ), we therefore find no compelling reason to assume that population-level competition was a primary driver of lamniform and carcharhiniform macroevolution in the deep past. ${ }^{37}$

\section{Implications for ecological evolution}

Sharks are usually portrayed as the quintessential generalists, capable of ingesting a wide variety of food items. ${ }^{38}$ While this may be true for species like the modern Galeocerdo cuvier $(\mathrm{OBD}=0.86)$, most selachimorphs display varying degrees of dietary specialization (Figure 5). ${ }^{39,40}$ Approximately $85 \%$ (47 out of 55) of extant lamniform and carcharhiniform species that we analyzed have ODBs $<0.5$ (Figures $5 A-5 C$ ), indicating a tendency toward more selective feeding. Unfortunately, without direct evidence from preserved gut contents, ${ }^{41}$ ODBs cannot be estimated for fossil sharks. Nonetheless, we detect a significant positive correlation between ODBs and morphospace loading along PC2 (Figure S5F). This correlation corresponds with positive loadings of lamniforms on $\mathrm{PC} 2$ following the $\mathrm{K} / \mathrm{Pg}$ boundary and perhaps implies a short-term selection toward more generalized diets across the extinction event. Conversely, negative loadings on PC2 after the Paleocene-Eocene thermal maximum (PETM) implicates lamniform and carcharhiniform specialization. The PETM triggered major extinctions among actinopterygians (e.g., tetraodontiforms) ${ }^{42}$ and presumably affected niche diversity among selachimorphs (e.g., Synechodontiformes). ${ }^{43}$ However, a shift toward more specialized diets during the PETM also coincided with the proliferation of biotically productive scleractinian coral reefs. ${ }^{44}$ These habitats are favored by carcharhiniforms today, especially carcharhinids, ${ }^{7,44}$ which underwent a disparity increase across the PETM (Figure S3C), potentially reflecting an adaptive accommodation of changing prey resource availability. ${ }^{45}$

While various developmental (e.g., palatoquadrate structure in lamniforms), ${ }^{46}$ reproductive (e.g., mating), behavioral (e.g., foraging habits), size-related (e.g., prey-size, body-size, and gape), ${ }^{35,43}$ and environmental (e.g., prey availability) ${ }^{40}$ constraints have influenced the evolution of shark dentitions, the primary function of their teeth is to capture and process prey, suggesting a link between tooth morphology and diet. ${ }^{14,38}$ Concomitantly, we evince a significant association between piscivory and mesiodistally compressed cuspidate anterior teeth (Figures 4C, 4D, and S4A-S4F), such as those of the sand tiger shark (Carcharias taurus), as well as with elongate "needlelike" teeth exemplified by Mitsukurina owstoni. The radiation of odontaspidid and mitsukurinid lamniforms during the early Paleogene could therefore correlate with an extinction-mediated shift toward generalized predation on teleosts. ${ }^{9}$ Piscivorous carcharhiniforms with low-crowned, distally recurved teeth, including catsharks (scyliorhinids), requiem sharks (carcharhinids), hound sharks (triakids), and weasel sharks (hemigaleids), ${ }^{8,47}$ might have similarly diversified through trophic cascades instigated by changing prey resources and habitats. ${ }^{9}$ Certainly, these are the most speciose carcharhiniform clades today (Scyliorhinidae comprising 160 species, Carcharhinidae 56 species, and Triakidae 46 species), ${ }^{7}$ potentially linking their Cenozoic diversification with shifts toward distally recurved tooth morphologies after the K/Pg boundary (Figure S6).

The early Paleogene trend toward increasingly low-crowned, distally recurved tooth morphologies in carcharhiniforms 


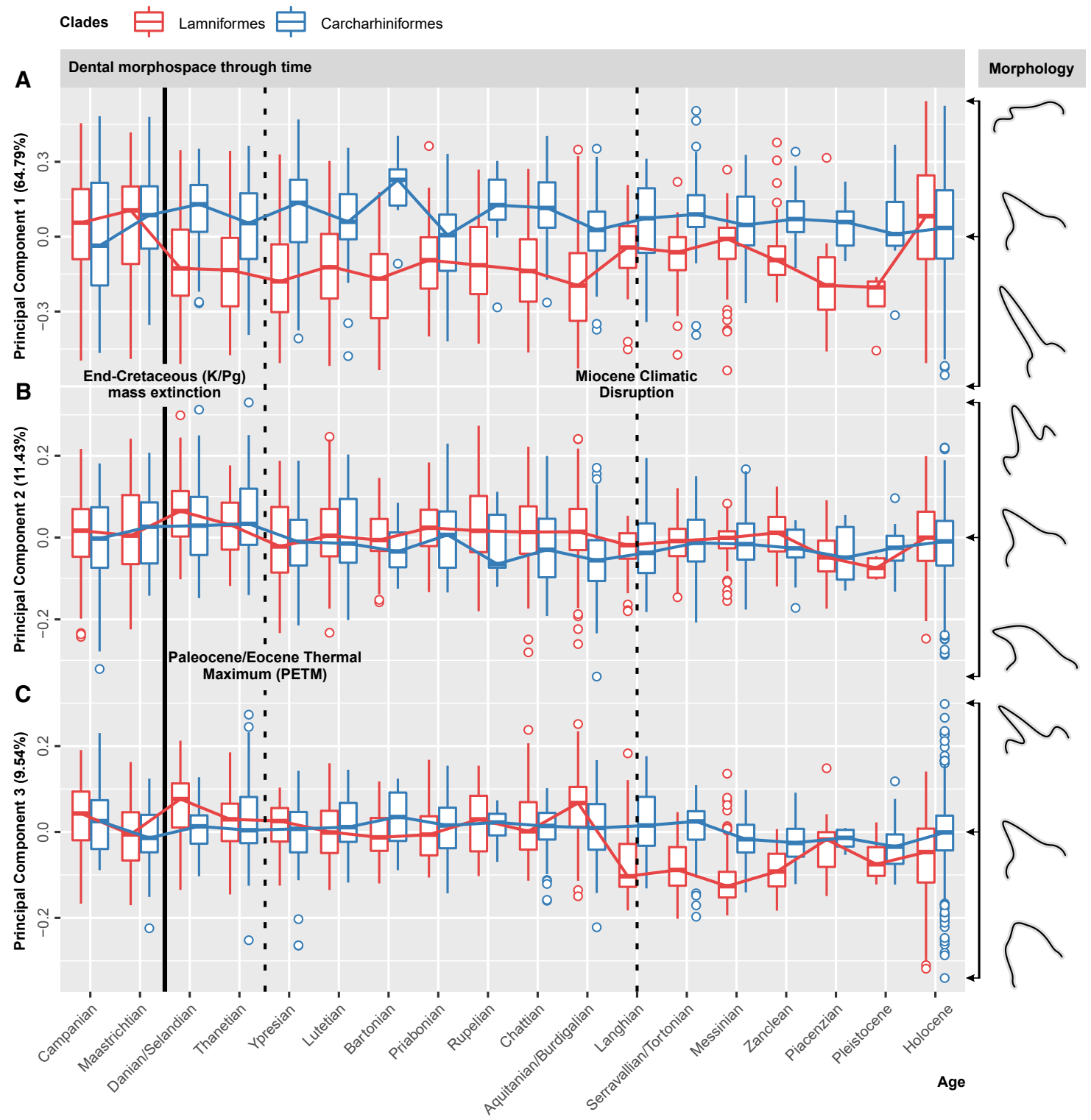

Figure 3. Dental morphospace through time

Box and whiskers plots depicting lamniform (red) and carcharhiniform (blue) tooth morphologies on (A) PC1, (B) PC2, and (C) PC3. Visualization indicates the median (center line), $25 \%$ and $75 \%$ hinges (box), and whiskers and outliers (open circles). Tooth outlines (right) depict hypothetical morphologies at the minimum and maximum axis values. Sample sizes for each clade are listed in Data S1B and S1F. See also Figures S2, S6, and S7 for additional morphospace results.

(Figure 3A) also corresponds with feeding on decapod crustaceans (e.g., the extant bonnethead shark, Sphyrna tiburo, and common smooth-hound, Mustelus mustelus; Figures $4 \mathrm{E}$ and 4F). Such morphologies are particularly abundant after the PETM, which we ascribe to an ecological expansion coincident with geographic dispersals and cladogenesis. ${ }^{48}$ Lamniforms, on the other hand, segregated into only a few distinctive dental morphologies that suffered synchronized disparity contractions during the mid-Miocene-early Pliocene (Figure 2A)-a time frame commenced by the global mid-Miocene climatic disruption. ${ }^{49}$ These contractions are most evident among lamnids and otodontids (Figures S3B and S7), ${ }^{8}$ which are lineages typified by apex predators, such as Otodus megalodon with an estimated maximum body length of $20 \mathrm{~m} .{ }^{50}$ Otodus megalodon possessed high-crowned triangular teeth that closely resemble those of Carcharodon carcharias and was probably likewise specialized for feeding on marine tetrapods (e.g., cetaceans and pinnipeds) as an adult. The decline of lamniform apex predators across the mid-Miocene-early Pliocene has been attributed to climate change and competition ${ }^{51-53}$ but was possibly also influenced by niche specialization limiting their responsive capacity to environmental alterations.

\section{Implications for modern shark disparity}

The disparity peak among extant lamniforms and carcharhiniforms (Figure 2A) is robust to rarefaction subsampling and 


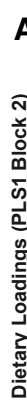

A

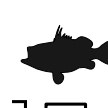
PLS1 Block 2 Loadings (Diet)

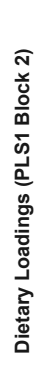

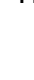

rents
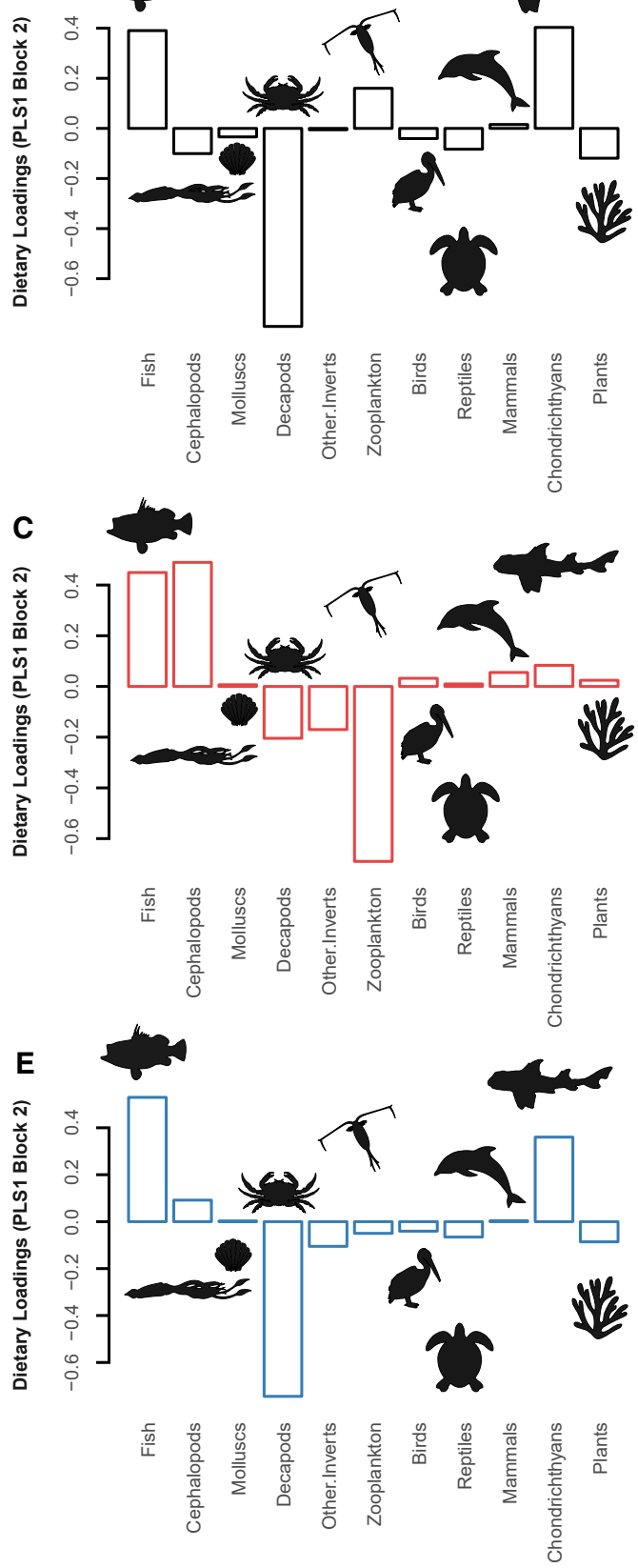

B

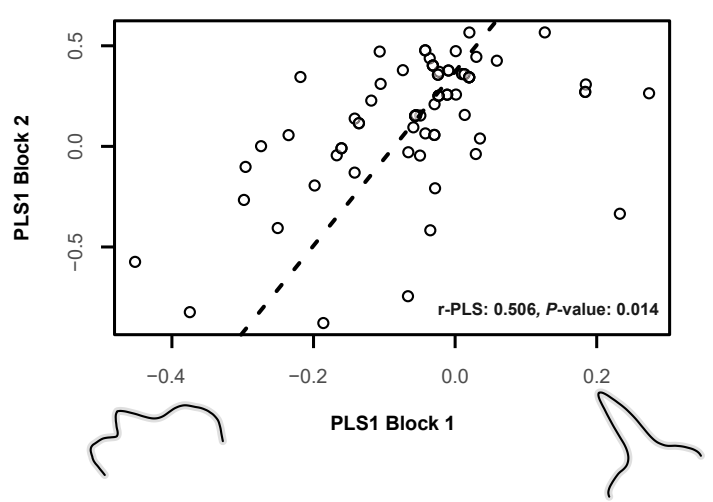

D

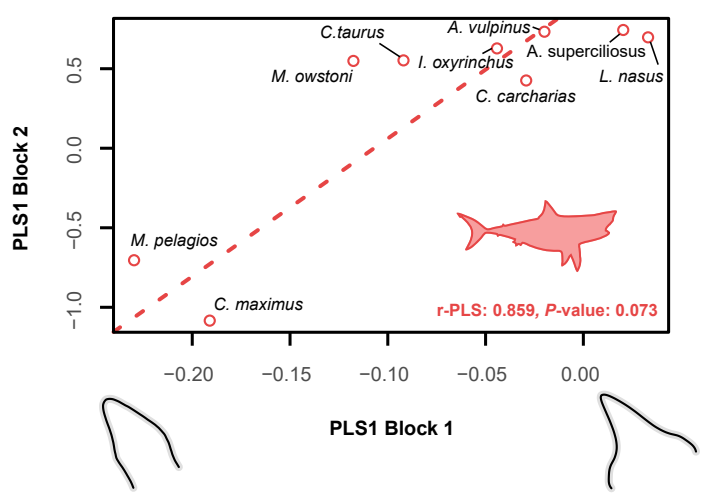

$\mathbf{F}$

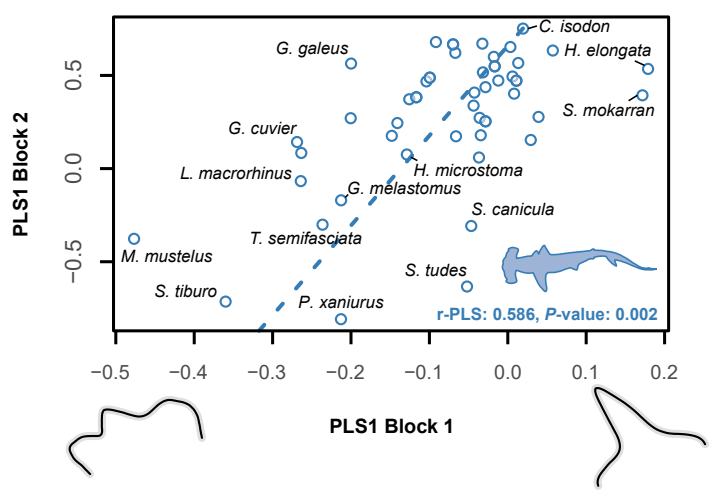

Figure 4. Morphological covariance with diet along PLS1

Bar plots (left) show PLS1 loadings for each food item category compared with bivariate plots (right) of morphology (block 1) versus diet (block 2) covariance. (A and B) Complete dataset $(n=55)$, (C and D) lamniforms $(n=9)$, and $(E$ and $F)$ carcharhiniforms $(n=46)$ are shown. Tooth outlines below bivariate plots depict hypothetical morphologies at minimum and maximum axis values along block 1 of PLS1. See also Figures S4 and S5 for additional ecomorphological results.

demonstrates that sample size alone cannot explain our results for these groups (see discussion at https://doi.org/10.5061/ dryad.h70rxwdjx). However, elevated extant disparity is undoubtedly influenced by the comprehensive sampling of living versus fossil species. For instance, geographic coverage in the fossil record is not equivalent to that of today (Figure S1). Irrespectively, we note that our elevated modern disparity follows an increasing trend that commenced during the late Pliocene
(Figure 2A): a signal that is unaffected by heterodonty. Heterodonty can enhance food processing and prey utilization (e.g., as observed in the bull shark, Carcharhinus leucas). ${ }^{54}$ Yet it can also accompany dietary specialization, as in the sicklefin weasel shark (Hemigaleus microstoma), which feeds primarily on cephalopods. ${ }^{55}$ As a result, monognathic heterodonty (calculated as disparity within a single jaw) does not strictly correlate with our ODB values (Figures S5C and S5D), implying that niche 
A

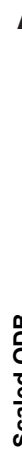

ब $\frac{5}{3}$

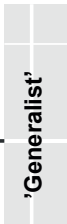

Prionace glauca $0^{0}$

o

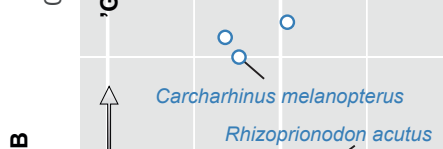
Galeocerdo cuvier
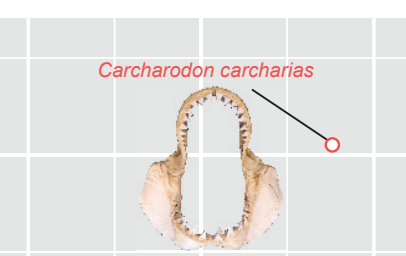

○

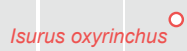

Isurus oxyrinchus

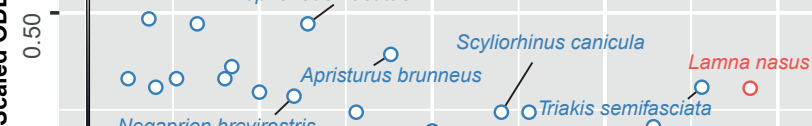

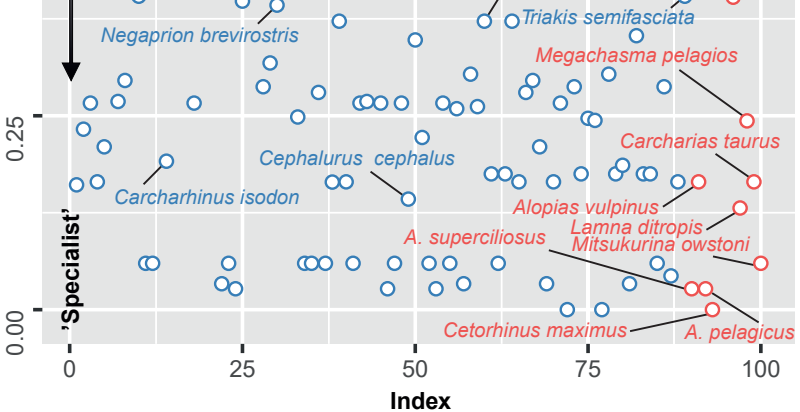

Clades $\bigcirc$ Lamniformes $\bigcirc$ Carcharhiniformes

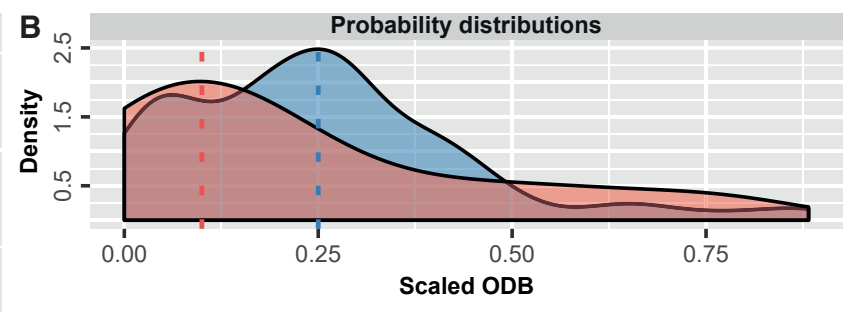

- - Modal
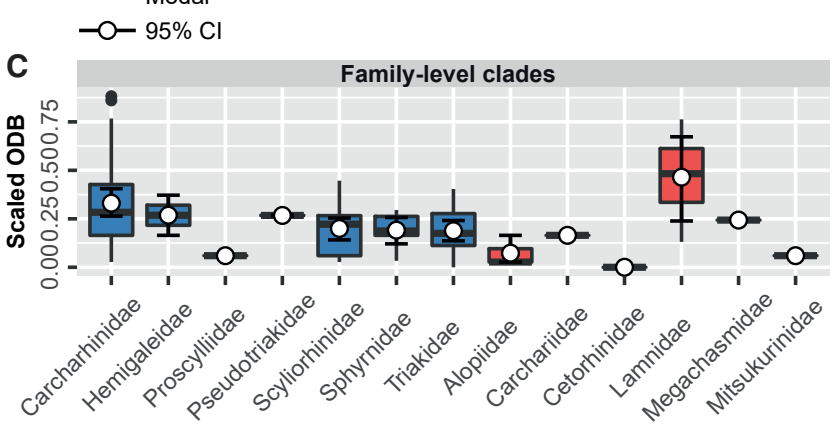

Figure 5. Ordinated dietary breadths (ODBs)

(A) Scatterplot showing scaled ODB distributions for lamniforms (red) and carcharhiniforms (blue) ranging from "specialist" (low ODBS) to "generalist" (high ODBs) feeding ecologies. Index, order of species in the dataset.

(B) Probability distributions with associated modalities for lamniform (red) and carcharhiniform (blue) ODBs.

(C) Box-and-whisker plot showing scaled ODB distributions for each family-level clade.

See Figure S5 for exploration of ODB with intraspecific heterodonty and morphology.

breadth (as defined by variation in feeding ecology) does not constrain within-jaw dental variation in living lamniforms and carcharhiniforms.

Comparisons with Late Cretaceous lamniforms (Figure 2A) show that extant species manifest less negatively skewed tooth morphologies $\left(g 1_{\mathrm{PC} 1}\right.$ :Maastrichtian $=-0.592$ versus $g 1_{\mathrm{PC} 1}$ : Holocene $=$ -0.016; Figure 3A). ${ }^{9}$ Positive PC1 values correspond to apex predators, such as Carcharodon carcharias, and zooplanktivores, including Cetorhinus maximus. Therefore, we posit that the decline of lamniform tooth disparity during the Cenozoic was possibly related to an asymmetrical erosion of morphospace, ${ }^{9}$ in which extant lamniforms parallel the disparity, but not the ecology, of their more diverse Mesozoic antecedents. Nevertheless, our ODBs (Figure 5B) highlight the dietary specialization of extant lamniforms (note that $C$. carcharias exhibits ontogenetic dietary changes toward specialization: see discussion at https://doi.org/10.5061/dryad.h70rxwdjx), ${ }^{56}$ and their corresponding extinction susceptibility, ${ }^{57,58}$ as was observed across the K/Pg boundary. Despite their noted asymmetrical diversity, we discovered that extant lamniforms are more disparate than their taxonomically richer carcharhiniform contemporaries, planting lamniforms as "numerical relicts," the surviving members of a far more speciose group in the distant geologic past. ${ }^{59}$

\section{Conclusions}

The drivers of morphological disparity are complex and, in the case of sharks, have involved an interplay of various abiotic and biotic factors. Our geometric morphometric analysis of the exceptionally rich 83-Ma dental fossil record of lamniforms and carcharhiniforms shows that feeding ecology, coupled with sea-level and temperature change, were primary regulators of their deep-time evolution. Despite the confounding biases of geologic sampling and intraspecific variation through heterodonty, we pinpoint the end-Cretaceous mass extinction, PETM, and mid-Miocene climatic disruption as pivotal events affecting lamniform and carcharhiniform dental morphology, ecology, and diversity. In particular, major turnovers among lamniforms can be correlated with dietary specialization and the loss of apex predator lineages at the $\mathrm{K} / \mathrm{Pg}$ and mid-Miocene transitions. We therefore recognize food resource and habitat utilization as key predictors of extinction sensitivity and underscore their role in shaping the asymmetrical diversity of lamniform and carcharhiniform sharks today.

\section{STAR $\star$ METHODS}

Detailed methods are provided in the online version of this paper and include the following:

- KEY RESOURCES TABLE

- RESOURCE AVAILABILITY

○ Lead contact

O Materials availability

O Data and code availability

- EXPERIMENTAL MODEL AND SUBJECT DETAILS

$\bigcirc$ Conceptual background and limitations 
- METHOD DETAILS

○ Institutional abbreviations

- Data sources and geographic context

- Temporal scope

○ Environmental data

○ Geometric morphometrics

- QUANTIFICATION AND STATISTICAL ANALYSIS

- Multivariate ordination and visualization

○ Randomization test

O Disparity and rarefaction

$\circ$ Generalized least-squares models

- Effects of heterodonty on disparity

- Ecomorphological analyses

○ Ordinated dietary niche breadth

\section{SUPPLEMENTAL INFORMATION}

Supplemental information can be found online at https://doi.org/10.1016/j. cub.2021.09.028.

\section{ACKNOWLEDGMENTS}

Our research was supported by a scholarship from E. and K.G. Lennanders Foundation to M.B. and a Wallenberg Scholarship from the Knut and Alice Wallenberg Foundation to P.E.A. N.E.C. is funded by an Australian Research Council Discovery Early Career Research Award (DE190101423). B.P.K. acknowledges a Swedish Research Council Project Grant (2020-3423). C.P. is financed by a PRIMA grant from the Swiss National Science Foundation. We thank Terry Gates (North Carolina State University), Mikael Siversson (Western Australian Museum), Dean Adams (lowa State University), Göran Arnqvist (Uppsala University), and Matt Friedman (University of Michigan) for images and discussions. Jürgen Kriwet (University of Vienna) and two anonymous reviewers contributed constructive comments that improved the manuscript.

\section{AUTHOR CONTRIBUTIONS}

M.B. designed analytical protocols, collected and analyzed the data, created the figures, and wrote the manuscript. N.E.C. designed analytical protocols, contributed data, and wrote the manuscript. B.P.K. contributed to data interpretation and wrote the manuscript. M.B., N.E.C., B.P.K., and P.E.A. conceived the project. All authors were involved in discussing the results and revising the manuscript.

\section{DECLARATION OF INTERESTS}

The authors declare no competing interests.

Received: January 15, 2021

Revised: June 5, 2021

Accepted: September 9, 2021

Published: October 5, 2021

\section{REFERENCES}

1. Foote, M. (1997). The evolution of morphological diversity. Annu. Rev. Ecol. Syst. 28, 129-152.

2. Benton, M.J. (2015). Exploring macroevolution using modern and fossil data. Proc. Biol. Sci. 282, 20150569.

3. Jablonski, D. (2020). Developmental bias, macroevolution, and the fossil record. Evol. Dev. 22, 103-125.

4. Gascuel, F., Ferrière, R., Aguilée, R., and Lambert, A. (2015). How ecology and landscape dynamics shape phylogenetic trees. Syst. Biol. 64, 590-607.

5. Kirxpatrick, M., and Slatkin, M. (1993). Searching for evolutionary patterns in the shape of a phylogenetic tree. Evolution 47, 1171-1181.
6. Mooers, A.O., and Heard, S.B. (1997). Inferring evolutionary process from phylogenetic tree shape. Q. Rev. Biol. 72, 31-54.

7. Ebert, D.A., Fowler, S.L., and Compagno, L.J. (2013). Sharks of the World: A Fully Illustrated Guide (Wild Nature).

8. Guinot, G., and Cavin, L. (2016). 'Fish' (Actinopterygii and Elasmobranchii) diversification patterns through deep time. Biol. Rev. Camb. Philos. Soc. 91, 950-981.

9. Bazzi, M., Kear, B.P., Blom, H., Ahlberg, P.E., and Campione, N.E. (2018). Static dental disparity and morphological turnover in sharks across the end-Cretaceous mass extinction. Curr. Biol. 28, 2607-2615.e3.

10. Condamine, F.L., Romieu, J., and Guinot, G. (2019). Climate cooling and clade competition likely drove the decline of lamniform sharks. Proc. Natl. Acad. Sci. USA 116, 20584-20590.

11. Smith, M.M. (2003). Vertebrate dentitions at the origin of jaws: when and how pattern evolved. Evol. Dev. 5, 394-413.

12. Rasch, L.J., Martin, K.J., Cooper, R.L., Metscher, B.D., Underwood, C.J., and Fraser, G.J. (2016). An ancient dental gene set governs development and continuous regeneration of teeth in sharks. Dev. Biol. 415, 347-370.

13. Martin, K.J., Rasch, L.J., Cooper, R.L., Metscher, B.D., Johanson, Z., and Fraser, G.J. (2016). Sox2+ progenitors in sharks link taste development with the evolution of regenerative teeth from denticles. Proc. Natl. Acad. Sci. USA 113, 14769-14774.

14. Cappetta, H. (2012). Handbook of Paleoichthyology Volume 3E: Chondrichthyes - Mesozoic and Cenozoic Elasmobranchii: Teeth (Verlag Dr. Friedrich Pfeil).

15. Friedman, M., and Sallan, L.C. (2012). Five hundred million years of extinction and recovery: A phanerozoic survey of large-scale diversity patterns in fishes. Palaeontology 55, 707-742.

16. Kriwet, J., and Benton, M.J. (2004). Neoselachian (Chondrichthyes, Elasmobranchii) diversity across the Cretaceous-Tertiary boundary. Palaeogeogr. Palaeoclimatol. Palaeoecol. 214, 181-194.

17. Belben, R.A., Underwood, C.J., Johanson, Z., and Twitchett, R.J. (2017). Ecological impact of the end-Cretaceous extinction on lamniform sharks. PLOS ONE 12, e0178294.

18. Evans, A.R., Wilson, G.P., Fortelius, M., and Jernvall, J. (2007). High-level similarity of dentitions in carnivorans and rodents. Nature 445, 78-81.

19. Melstrom, K.M. (2017). The relationship between diet and tooth complexity in living dentigerous saurians. J. Morphol. 278, 500-522.

20. Foote, M. (1993). Contributions of individual taxa to overall morphological disparity. Paleobiology 19, 403-419.

21. Zelditch, M.L., Swiderski, D.L., and Sheets, H.D. (2012). Geometric Morphometrics for Biologists (Academic).

22. Cortés, E. (1999). Standardized diet compositions and trophic levels of sharks. ICES J. Mar. Sci. 56, 707-717.

23. Van Valen, L. (1973). A new evolutionary law. Evol. Theory 1, 1-30.

24. Barnosky, A.D. (2001). Distinguishing the effects of the red queen and court jester on miocene mammal evolution in the northern Rocky Mountains. J. Vertebr. Paleontol. 21, 172-185.

25. Westerhold, T., Marwan, N., Drury, A.J., Liebrand, D., Agnini, C., Anagnostou, E., Barnet, J.S.K., Bohaty, S.M., De Vleeschouwer, D., Florindo, F., et al. (2020). An astronomically dated record of Earth's climate and its predictability over the last 66 million years. Science 369, 13831387.

26. Miller, K.G., Browning, J.V., Schmelz, W.J., Kopp, R.E., Mountain, G.S., and Wright, J.D. (2020). Cenozoic sea-level and cryospheric evolution from deep-sea geochemical and continental margin records. Sci. Adv. 6, eaaz1346.

27. Fordyce, J.A., Nice, C.C., Hamm, C.A., and Forister, M.L. (2016) Quantifying diet breadth through ordination of host association. Ecology 97, 842-849.

28. Ray, D.C., van Buchem, F.S.P., Baines, G., Davies, A., Gréselle, B., Simmons, M.D., and Robson, C. (2019). The magnitude and cause of 
short-term eustatic Cretaceous sea-level change: a synthesis. Earth Sci. Rev. 197, 102901.

29. Siversson, M., Lindgren, J., Newbrey, M.G., Cederström, P., and Cook, T.D. (2015). Cenomanian-Campanian (Late Cretaceous) mid-palaeolatitude sharks of Cretalamna appendiculata type. Acta Palaeontol. Pol. 60, 339-384.

30. Bazzi, M., Campione, N.E., Ahlberg, P.E., Blom, H., and Kear, B.P. (2021). Tooth morphology elucidates shark evolution across the end-Cretaceous mass extinction. PLoS Biol. 19, e3001108.

31. Liow, L.H., Di Martino, E., Voje, K.L., Rust, S., and Taylor, P.D. (2016). Interspecific interactions through 2 million years: are competitive outcomes predictable? Proc. Biol. Sci. 283, 20160981.

32. Weber, M.G., Wagner, C.E., Best, R.J., Harmon, L.J., and Matthews, B. (2017). Evolution in a community context: on integrating ecological interactions and macroevolution. Trends Ecol. Evol. 32, 291-304.

33. Rillo, M.C., Sugawara, M.T.C., Cabella, B., Jonkers, L., Baranowski, U.K., Kučera, M., and Ezard, T.H.G. (2019). On the mismatch in the strength of competition among fossil and modern species of planktonic Foraminifera. Glob. Ecol. Biogeogr. 28, 1866-1878.

34. Marshall, C.R., and Quental, T.B. (2016). The uncertain role of diversity dependence in species diversification and the need to incorporate timevarying carrying capacities. Philos. Trans. R. Soc. Lond. B Biol. Sci. 371, 20150217.

35. Block, B.A., Jonsen, I.D., Jorgensen, S.J., Winship, A.J., Shaffer, S.A., Bograd, S.J., Hazen, E.L., Foley, D.G., Breed, G.A., Harrison, A.L., et al. (2011). Tracking apex marine predator movements in a dynamic ocean. Nature 475, 86-90.

36. Lear, K.O., Whitney, N.M., Morris, J.J., and Gleiss, A.C. (2021). Temporal niche partitioning as a novel mechanism promoting co-existence of sympatric predators in marine systems. Proc. Biol. Sci. 288, 20210816.

37. Dudley, S.F.J., Anderson-Reade, M.D., Thompson, G.S., and McMullen, P.B. (2000). Concurrent scavenging off a whale carcass by great white sharks, Carcharodon carcharias, and tiger sharks, Galeocerdo cuvier. Fish Bull. 98, 646-649.

38. Huber, D., Wilga, C., Dean, M., Ferry, L., Gardiner, J., Habegger, L., Papastamatiou, Y., Ramsay, J., and Whitenack, L. (2019). Feeding in Cartilaginous Fishes: An Interdisciplinary Synthesis (Springer), pp. 231-295.

39. Munroe, S.E.M., Simpfendorfer, C.A., and Heupel, M.R. (2014). Defining shark ecological specialisation: concepts, context, and examples. Rev. Fish Biol. Fish. 24, 317-331.

40. Crooks, N. (2020). Chondrichthyes diet. In Encyclopedia of Animal Cognition and Behavior, J. Vonk, and T. Shackelford, eds. (Springer).

41. Fanti, F., Minelli, D., Conte, G.L., and Miyashita, T. (2016). An exceptionally preserved Eocene shark and the rise of modern predator-prey interactions in the coral reef food web. Zoological Lett. 2, 9.

42. Arcila, D., and Tyler, J.C. (2017). Mass extinction in tetraodontiform fishes linked to the Palaeocene-Eocene thermal maximum. Proc. Biol. Sci. 284, 20171771.

43. Klug, S. (2010). Monophyly, phylogeny and systematic position of the $\dagger$ synechodontiformes (Chondrichthyes, Neoselachii). Zool. Scr. 39, 37-49.

44. Sorenson, L., Santini, F., and Alfaro, M.E. (2014). The effect of habitat on modern shark diversification. J. Evol. Biol. 27, 1536-1548.

45. Bellwood, D.R., and Wainwright, P.C. (2002). The history and biogeography of fishes on coral reefs. In Coral Reef Fishes: Dynamics and Diversity in a Complex Ecosystem, P.F. Sale, ed. (Academic), pp. 5-32.

46. Siverson, M. (1999). A new large lamniform shark from the uppermost Gearle Siltstone (Cenomanian, Late Cretaceous) of Western Australia. Trans. R. Soc. Edinb. Earth Sci. 90, 49-66.

47. Maisey, J.G. (2012). What is an 'elasmobranch'? The impact of palaeontology in understanding elasmobranch phylogeny and evolution. J. Fish Biol. $80,918-951$.
48. Gallagher, A.J., Hammerschlag, N., Shiffman, D.S., and Giery, S.T. (2014) Evolved for extinction: The cost and conservation implications of specialization in hammerhead sharks. Bioscience 64, 619-624.

49. Holbourn, A., Kuhnt, W., Kochhann, K.G.D., Andersen, N., and Sebastian Meier, K.J. (2015). Global perturbation of the carbon cycle at the onset of the Miocene Climatic Optimum. Geology 43, 123-126.

50. Perez, V.J., Leder, R.M., and Badaut, T. (2021). Body length estimation of Neogene macrophagous lamniform sharks (Carcharodon and Otodus) derived from associated fossil dentitions. Palaeontol. Electronica 24, a09.

51. Pimiento, C., MacFadden, B.J., Clements, C.F., Varela, S., Jaramillo, C., Velez-Juarbe, J., and Silliman, B.R. (2016). Geographical distribution patterns of Carcharocles megalodon over time reveal clues about extinction mechanisms. J. Biogeogr. 43, 1645-1655.

52. Boessenecker, R.W., Ehret, D.J., Long, D.J., Churchill, M., Martin, E., and Boessenecker, S.J. (2019). The Early Pliocene extinction of the megatoothed shark Otodus megalodon: a view from the eastern North Pacific. PeerJ 7, e6088.

53. Sibert, E.C., and Rubin, L.D. (2021). An early Miocene extinction in pelagic sharks. Science 372, 1105-1107.

54. Cullen, J.A., and Marshall, C.D. (2019). Do sharks exhibit heterodonty by tooth position and over ontogeny? A comparison using elliptic Fourier analysis. J. Morphol. 280, 687-700.

55. Stevens, J.D., and Cuthbert, G.J. (1983). Observations on the identification and biology of Hemigaleus (Selachii: Carcharhinidae) from Australian waters. Copeia 1983, 487-497.

56. Hussey, N.E., and Dudley, S.F.J. (2012). Size-based analysis of diet and trophic position of the white shark, Carcharodon carcharias, in South African waters. In Global Perspectives on the Biology and Life History of the White Shark, M.L. Domeier, ed. (CRC), pp. 27-49.

57. García, V.B., Lucifora, L.O., and Myers, R.A. (2008). The importance of habitat and life history to extinction risk in sharks, skates, rays and chimaeras. Proc. Biol. Sci. 275, 83-89.

58. Stein, R.W., Mull, C.G., Kuhn, T.S., Aschliman, N.C., Davidson, L.N.K., Joy, J.B., Smith, G.J., Dulvy, N.K., and Mooers, A.O. (2018). Global priorities for conserving the evolutionary history of sharks, rays and chimaeras. Nat. Ecol. Evol. 2, 288-298.

59. Brooks, D.R., and Bandoni, S.M. (1988). Coevolution and relicts. Syst. Zool. 37, 19-33.

60. Zachos, J.C., Dickens, G.R., and Zeebe, R.E. (2008). An early Cenozoic perspective on greenhouse warming and carbon-cycle dynamics. Nature 451, 279-283.

61. Prokoph, A., Shields, G.A., and Veizer, J. (2008). Compilation and time-series analysis of a marine carbonate $\delta^{18} \mathrm{O}, \delta^{13} \mathrm{C},{ }^{87} \mathrm{Sr} /{ }^{86} \mathrm{Sr}$ and $\delta^{34} \mathrm{~S}$ database through Earth history. Earth Sci. Rev. 87, 113-133.

62. Miller, K.G., Kominz, M.A., Browning, J.V., Wright, J.D., Mountain, G.S., Katz, M.E., Sugarman, P.J., Cramer, B.S., Christie-Blick, N., and Pekar, S.F. (2005). The phanerozoic record of global sea-level change. Science 310, 1293-1298.

63. Yano, K., Miya, M., Aizawa, M., and Noichi, T. (2007). Some aspects of the biology of the goblin shark, Mitsukurina owstoni, collected from the Tokyo Submarine Canyon and adjacent waters, Japan. Ichthyol. Res. 54, 388-398.

64. Bizzarro, J.J., Carlisle, A.B., Smith, W.D., and Cortés, E. (2017). Diet composition and trophic ecology of Northeast Pacific Ocean sharks. Adv. Mar. Biol. 77, 111-148.

65. González-Pestana, A., Acuña-Perales, N., Córdova, F., Coasaca, J., Alfaro, E., Alfaro-Shigueto, J., and Mangel, J.C. (2019). Feeding habits of thresher sharks Alopias sp. in northern Peru: predators of Humboldt squid (Dosidicus gigas). J. Mar. Biol. Assoc. U.K. 99, 695-702.

66. Rohlf, F.J. (2016). tpsDig. http://www.sbmorphometrics.org/.

67. R Development Core Team (2019). R: A language and environment for statistical computing (R Foundation for Statistical Computing). 
68. Adams, D.C., Collyer, M.L., and Kaliontzopoulou, A. (2019). Geomorph: software for geometric morphometric analyses. R package version 3.1.0. https://cran.r-project.org/package=geomorph.

69. Collyer, M.L., and Adams, D.C. (2018). RRPP: an R package for fitting linear models to high-dimensional data using residual randomization. Methods Ecol. Evol. 9, 1772-1779.

70. Pinheiro, J., Bates, D., DebRoy, S., and Sarkar, D.; R Core Team (2019). nmle: linear and nonlinear mixed effects models. $R$ package version 3.1143. https://CRAN.R-project.org/package=nlme.

71. Revell, L.J. (2012). phytools: an R package for phylogenetic comparative biology (and other things). Methods Ecol. Evol. 3, 217-223.

72. Pennell, M.W., Eastman, J.M., Slater, G.J., Brown, J.W., Uyeda, J.C., FitzJohn, R.G., Alfaro, M.E., and Harmon, L.J. (2014). geiger v2.0: an expanded suite of methods for fitting macroevolutionary models to phylogenetic trees. Bioinformatics 30, 2216-2218.

73. Stone, N.R., and Shimada, K. (2019). Skeletal anatomy of the bigeye sand tiger shark, Odontaspis noronhai (Lamniformes: Odontaspididae), and its implications for lamniform phylogeny, taxonomy, and conservation biology. Copeia 107, 632-652.

74. Siverson, M., and Lindgren, J. (2005). Late Cretaceous sharks Cretoxyrhina and Cardabiodon from Montana, USA. Acta Palaeontol. Pol. 50, 301-314.
75. Marx, F.G., and Uhen, M.D. (2010). Climate, critters, and cetaceans: Cenozoic drivers of the evolution of modern whales. Science 327 , 993-996.

76. Mardia, K.V., and Dryden, I.L. (1989). The statistical analysis of shape data. Biometrika 76, 271-281.

77. Benjamini, Y., and Hochberg, Y. (1995). Controlling the false discovery rate: a practical and powerful approach to multiple testing. J. R. Stat. Soc. B 57, 289-300.

78. Pinheiro, J.C., and Bates, D.M. (2000). Mixed-Effects Models in S and S-PLUS (Springer-Verlag).

79. Cohen, K.M., Finney, S.C., Gibbard, P.L., and Fan, J.-X. (2013). The ICS international chronostratigraphic chart. Episodes 36, 199-204.

80. Rohlf, F.J., and Corti, M. (2000). Use of two-block partial least-squares to study covariation in shape. Syst. Biol. 49, 740-753.

81. Collyer, M.L., Sekora, D.J., and Adams, D.C. (2015). A method for analysis of phenotypic change for phenotypes described by high-dimensional data. Heredity $115,357-365$.

82. Bookstein, F.L. (1989). Principal warps: thin-plate splines and the decomposition of deformations. IEEE Trans. Pattern Anal. Mach. Intell. 11, 567-585.

83. Bookstein, F.L. (1992). Morphometric Tools for Landmark Data (Cambridge University). 


\section{STAR $\star M E T H O D S$}

\section{KEY RESOURCES TABLE}

\begin{tabular}{|c|c|c|}
\hline REAGENT or RESOURCE & SOURCE & IDENTIFIER \\
\hline \multicolumn{3}{|l|}{ Deposited data } \\
\hline Morphometric data sources & This paper & Data S1; https://doi.org/10.5061/dryad.h70rxwdjx \\
\hline Table Results & This paper & Data S2; https://doi.org/10.5061/dryad.h70rxwdjx \\
\hline Supplementary results and methods & This paper & $\begin{array}{l}\text { Data Dryad Supplementary File 1; https://doi.org/ } \\
\text { 10.5061/dryad.h70rxwdjx }\end{array}$ \\
\hline Landmark coordinate data & This paper & $\begin{array}{l}\text { Data Dryad Supplementary File 2; https://doi.org/ } \\
\text { 10.5061/dryad.h70rxwdjx }\end{array}$ \\
\hline Sliders file & This paper & $\begin{array}{l}\text { Data Dryad Supplementary File 3; https://doi.org/ } \\
\text { 10.5061/dryad.h70rxwdjx }\end{array}$ \\
\hline Maximum clade credibility tree & Stein et al. ${ }^{58}$ & $\begin{array}{l}\text { Data Dryad Supplementary File 4; https://doi.org/ } \\
\text { 10.5061/dryad.h70rxwdjx }\end{array}$ \\
\hline Environmental dataset 1 & $\begin{array}{l}\text { Zachos et al., }{ }^{60} \text { Prokoph et al., }{ }^{61} \text { and } \\
\text { Miller et al. }{ }^{62}\end{array}$ & $\begin{array}{l}\text { Data Dryad Supplementary File 5; https://doi.org/ } \\
\text { 10.5061/dryad.h70rxwdjx }\end{array}$ \\
\hline Environmental dataset 2 & Westerhold et al. ${ }^{25}$ and Miller et al. ${ }^{26}$ & $\begin{array}{l}\text { Data Dryad Supplementary File 6; https://doi.org/ } \\
\text { 10.5061/dryad.h70rxwdjx }\end{array}$ \\
\hline $\begin{array}{l}\text { Diet compositions and trophic levels } \\
\text { of sharks }\end{array}$ & $\begin{array}{l}\text { Cortés, }{ }^{22} \text { Yano et al., }{ }^{63} \text { Bizzarro et al.., } \\
\text { and González-Pestana et al. }{ }^{65}\end{array}$ & $\begin{array}{l}\text { Data Dryad Supplementary File 7; https://doi.org/ } \\
\text { 10.5061/dryad.h70rxwdjx }\end{array}$ \\
\hline $\begin{array}{l}\text { Diet of Successive Size Classes of } \\
\text { White Shark }\end{array}$ & Hussey and Dudley ${ }^{56}$ & $\begin{array}{l}\text { Data Dryad Supplementary File 8; https://doi.org/ } \\
\text { 10.5061/dryad.h70rxwdjx }\end{array}$ \\
\hline R source code & This paper & R Scripts; https://doi.org/10.5061/dryad.h70rxwdjx \\
\hline \multicolumn{3}{|l|}{ Software and algorithms } \\
\hline tpsDig2 & Rohlf $^{66}$ & http://www.sbmorphometrics.org/ \\
\hline $\mathrm{R}$ & R Development Core Team ${ }^{67}$ & https://www.r-project.org/ \\
\hline geomorph (R package) & Adams et al. ${ }^{68}$ & 4.0 .0 \\
\hline RRPP (R package) & Collyer and Adams ${ }^{69}$ & 1.0 .0 \\
\hline nlme (R package) & Pinheiro et al. ${ }^{70}$ & $3.1-145$ \\
\hline ordiBreadth (R package) & Fordyce et al. ${ }^{27}$ & 1.0 \\
\hline phytools (R package) & Revell $^{71}$ & $0.7-20$ \\
\hline geiger (R package) & Pennell et al. ${ }^{72}$ & 2.0 .7 \\
\hline
\end{tabular}

\section{RESOURCE AVAILABILITY}

\section{Lead contact}

Further information on materials, datasets, and protocols should be directed to and will be fulfilled by the Lead Contact, Mohamad Bazzi (mohamad.bazzi@uzh.ch).

\section{Materials availability}

The landmark coordinate data used in all the analyses can be accessed from Data Dryad under DOI: https://doi.org/10.5061/dryad. h70rxwdjx.

\section{Data and code availability}

All code used in this study and other previously published phylogenetic, ecological, and environmental data are available at the sources referenced in the Key resources table. Landmark data, the sliders file, R scripts, and other metadata are accessioned for open access on the Dryad data repository. 


\section{EXPERIMENTAL MODEL AND SUBJECT DETAILS}

\section{Conceptual background and limitations}

Our taxonomic designations were constrained at order- and family-level. We avoided analytical use of genus and species-level taxa because these classifications can be contentious for fossil sharks. In addition, the biotic drivers of lamniform and carcharhiniform diversity ${ }^{10}$ are ambiguous, as opposed to morphological variability, which provides a more direct proxy for ecological macroevolution. While dental morphology represents an unavoidably constrained dataset, it is demonstrably robust to confounding factors, such as sampling and intraspecific variability through heterodonty (see Data Dryad Supplemental File: https://doi.org/10.5061/dryad. h70rxwdjx). Nonetheless, we acknowledge that heterodonty is currently only evidenced in fossil lamniforms. Our disparity estimates for fossil carcharhiniforms may therefore be inflated, yet our lamniform-based results suggest that observed differences between time-bins are likely independent of tooth positional variation in both clades.

Uncertain family-level assignments necessitated some consensus referrals for convenience: (1) Carcharias taurus included in Carchariidae rather than Odontaspididae; ${ }^{73}$ (2) teeth attributed to the extinct genus Paranomotodon were treated as incertae sedis; (3) Cretoxyrhinidae was limited to the genus Cretoxyrhina; ${ }^{74}$ (4) Archaeolamnidae was limited to the genus Archaeolamna; (5) Otodontidae was limited to the genus Cretalamna. ${ }^{29}$ While family-level representations are incomplete for some time-bins, we found that these yielded recoverable patterns with which to interpret the coarser order-level analyses.

\section{METHOD DETAILS}

Institutional abbreviations

WAM, Western Australian Museum, Perth, Western Australia, Australia. ROM, Royal Ontario Museum, Toronto, Ontario, Canada. FMNH, Florida Museum of Natural History, Gainesville, Florida, U.S.A. NCMNS, North Carolina Museum of Natural Sciences, Raleigh, North Carolina, U.S.A.

\section{Data sources and geographic context}

We sourced primary images of fossil shark teeth from the literature (Data S1). Original photographs of teeth from extant species were obtained from specimens held in the collections of the WAM, ROM, FMNH, and NCMNS, with some also sourced with permission from Shark References (https://shark-references.com/), and J-Elasmo (http://www.elasmo.com/) (see Data Dryad Supplemental File: https://doi.org/10.5061/dryad.h70rxwdjx). We acknowledge that our geographic and stratigraphic information is subject to historical sampling biases, with assemblages from North America and Europe having disproportionate representation versus those from Asia and South America, which are usually restricted to Cretaceous and Paleogene deposits (Figure S1). Similarly, extant species sampling is largely restricted to catches recorded from the Atlantic, Pacific, and Indian oceans.

Temporal scope

We explored morphological variation over time using an age-based chronostratigraphic scale (Data S2). Initial assessments of our data indicated that sampling varied between time-bins. In particular, the Selandian, Aquitanian, and Serravallian were found to be data deficient. Consequently, to maximize data usage, we combined the Danian/Selandian, Aquitanian/Burdigalian, and Serravallian/Tortonian time-bins, and tested an Epoch-based time-scale for the Eocene, Oligocene, and Miocene (see Data Dryad Supplemental File: https://doi.org/10.5061/dryad.h70rxwdjx).

\section{Environmental data}

To evaluate abiotic drivers of lamniform and carcharhiniform dental evolution, we obtained a published dataset of sedimentary sealevel measures combined with $\delta^{18} \mathrm{O}$ values converted to deep-sea paleotemperatures ${ }^{10,60-62}$ (Environmental Dataset 1). We also evaluated a second dataset of $\delta^{18} \mathrm{O}$ estimates complied for the entire Cenozoic time interval ${ }^{25,28}$ (Environmental Dataset 2). These well-established climatic and eustatic proxies are recognized regulators of marine vertebrate biodiversity change, ${ }^{24,75}$ and have been employed in previous studies on lamniform and carcharhiniform macroevolution. ${ }^{10}$

\section{Geometric morphometrics}

Shape variables were acquired using two-dimensional landmark-based geometric morphometrics (GM). ${ }^{21}$ Fixed landmark and sliding semi-landmark designations followed published protocols for shark tooth image digitization. ${ }^{9,30}$ Digitization procedures were standardized to trace the outermost perimeter of each crown from its junction with the root toward the apex along the mesial and distal margins (Figures 1A and 1B). This resulted in two open curves comprising 157 sliding semi-landmarks and three fixed landmarks located at the tooth apex and the mesial and distal crown-root junctions (Figure 1B). Landmark digitization was performed in tpsDig2 v. $2.32^{66}$ with point equidistance and standardization routines written in $R$. Non-shape attributes of scale, orientation, and position were filtered from the landmark dataset using a generalized Procrustes analysis (GPA) implemented in the $R$ package 
geomorph v. 4.0.0. ${ }^{68}$ A bending energy criterion was computed during the GPA procedure to determine the final position of the sliding semi-landmarks.

\section{QUANTIFICATION AND STATISTICAL ANALYSIS}

All procedures and analyses were performed in the $R$ statistical environment v.4.0.5. ${ }^{67}$

Multivariate ordination and visualization

Tooth shape variation was visualized using a PCA of the covariance matrix obtained from the Procrustes shape coordinates. ${ }^{76}$ Morphospace was assessed across PC1-PC7; however, only PC1-PC3 were retained for further analysis (Figures S2, S6, and S7). Collectively, these axes summarize $\sim 86 \%$ of the variation and correspond to recognizable tooth morphotypes. ${ }^{9} \mathrm{~A}$ description of minimum and maximum morphologies associated with these axes is provided in the main text. Differences between time-bins and taxa were evaluated using a non-parametric analysis of variance (ANOVA) incorporating a randomized residual permutation procedure (RRPP) for hypothesis testing. ${ }^{69}$ A false discovery rate method was used to limit the rate of false positives in $p$ value statistics. ${ }^{77}$

\section{Randomization test}

Randomization tests of the extant sample used sub-sampling at predetermined intervals $(n=10,20,30,40)$ with replacement determined from the frequency distributions for each major clade. We limited testing to PC1 because this component captured the highest percentage of the morphological signal.

\section{Disparity and rarefaction}

Procrustes variance $(P V)$ was used to measure disparity directly from the Procrustes shape coordinates. ${ }^{68} \mathrm{PV}$ is defined as the summed squared distances of all observations to the grand mean divided by the degrees of freedom; this is equivalent to the covariance matrix trace divided by the number of observations, ${ }^{21}$ and computed using the morphol.disparity function in geomorph. Pairwise differences between time-bins were evaluated using the permutation procedure in geomorph. ${ }^{68}$

We applied rarefaction subsampling to investigate the effects of sample size on clade-specific and temporal disparity. Sub-sampling levels were determined from the lowest sampled time-bin in the data. Bootstrap prediction intervals were computed for raw and rarefied disparity using 999 pseudoreplicates.

\section{Generalized least-squares models}

Sedimentary sea-level and $\delta^{18} \mathrm{O}$ paleotemperature values were correlated with disparity using generalized least-squares (GLS) linear models with a maximum likelihood criterion for parameter estimation. Serial autocorrelation was assessed using complete (ACF) and partial autocorrelation functions (PACF), as well as Ljung-Box tests. ACF calculates the correlation between lagged residuals, ${ }^{78}$ whereas PACF determines the number of autoregressive $p$ orders needed for suitable model construction. Autocorrelations from both GLS and ordinary least-squares (OLS) linear model residuals were inspected by plotting a predetermined number of lags $\left(\rho_{k}=12\right)$ against their corresponding autocorrelations. Significant autocorrelations were deemed to be those outside $95 \%$ confidence intervals. Although we failed to detect any significant autocorrelations, models that included an autoregressive correlation structure received better support. We provide both GLS and OLS results.

To accommodate for contrasting time-binning schemes, ${ }^{26,59,73,74}$ we used arithmetic means for sedimentary sea-level and $\delta^{18} \mathrm{O}$ values allocated to each geochronological age. ${ }^{79}$ Five separate GLS models were fit to calculated disparities and evaluated using the Akaike Information Criterion corrected for small sample sizes (AICc) and likelihood ratio tests. GLS analyses were carried out over the latest Mesozoic-Cenozoic time bins and again over a Cenozoic-only time-bin subset. All GLS models were run using the gls function in nlme v 3.1-145. ${ }^{70}$

1. 'Null model'. Provides a single parameter intercept-only model whereby shark disparity was described as stochastic (= Brownian motion).

2. 'Sea-level model'. Provides a two-parameter slope + intercept model that described a relationship between changing sea-level and shark disparity.

3. ' $\delta{ }^{18} \mathrm{O}$ model'. Provides a two-parameter slope + intercept model that described a relationship between changing $\delta^{18} \mathrm{O}$ paleotemperature values and shark disparity.

4. 'Sea-level $+\delta^{18} \mathrm{O}$ model'. Provides a three-parameter slope + slope + intercept model that described a multivariate relationship between changing sea-level, $\delta^{18} \mathrm{O}$ paleotemperature values, and shark disparity.

5. 'Sea-level $\times \delta^{18} \mathrm{O}$ model'. Provides a four-parameter slope + slope + interaction + intercept model that described a multivariate relationship between changing sea-level, $\delta^{18} \mathrm{O}$ paleotemperature values, and the interaction between changing sea-level and $\delta^{18} \mathrm{O}$ paleotemperature values, together with shark disparity. 
Effects of heterodonty on disparity

We evaluated the potential effects of heterodonty in lamniforms via direct disparity and pairwise comparisons between time-bins (Figure S3). We used three separate morphological models:

1. A monognathic model $\left(n_{\text {Lamniformes }}=1345\right)$ with standardized tooth positions following the literature (Data S1). Monognathic positional categories include 'parasymphyseal', 'anterior', 'lateroposterior', and 'posterior'30. These were designated for convenience and do not correspond to strict anatomical configurations. ${ }^{46}$

2. A dignathic model $\left(n_{\text {Lamniformes }}=1196\right)$ differentiating the upper and lower dental units.

3. A combined-heterodonty model $\left(\mathrm{n}_{\text {Lamniformes }}=907\right)$ allowing for interaction between tooth positions and dental units.

\section{Ecomorphological analyses}

Lamniform and carcharhiniform diets were categorized using published gut contents recorded from live-caught specimens of 9 lamniform and 46 carcharhiniform species. ${ }^{22,63-65}$ Food item classifications included: tetrapods (mammals, birds, reptiles); osteichthyans; chondrichthyans; cephalopods; benthic molluscs; decapod crustaceans; other invertebrates; zooplankton; and plants. These data were transformed using arcsine square-roots and then subjected to a covariation analysis with the Procrustes coordinates via a two-block partial least-squares (PLS) analysis. ${ }^{80}$ Correlation coefficients $\left(r_{P L S}\right)$ were used to evaluate PLS strengths with a permutation procedure (RRPP at 999 iterations) for significance testing. ${ }^{69,81}$ Alternate correlations were also performed for all taxa, and again at order-level (Figures 4 and S4). In addition, we re-ran the lamniform-only analysis excluding specialized filterfeeding lamniforms, Cetorhinus maximus and Megachasma pelagios, which skewed the initial PLS analysis (Figure S5). Shape changes at the PLS axial extremes were visualized using thin-plate splines (TPSs). ${ }^{82,83}$

Finally, we computed a phylogenetic two-block PLS using the phylo.integration function in geomorph. Our preferred tree topology was pruned from the most inclusive molecular phylogeny ${ }^{58}$ and calibrated across 200 random trees with the maximum-clade credibility tree derived using phytools v. $0.7-20^{71}$ and the geomorph libraries. ${ }^{68}$

\section{Ordinated dietary niche breadth}

Ordinated dietary niche breadths (ODBs) were calculated at species-level $\left(n_{\text {species }}=100\right)$ using a pairwise Jaccard dissimilarity matrix of 'presence/absence' food item category scores, ${ }^{22}$ and analyzed with the ordiBreadth v.1.0 package. ${ }^{27}$ The dissimilarity matrix was then ordinated through a principal coordinates analysis $(\mathrm{PCoA})$ from which $\mathrm{ODB}_{\text {rawi }}$ is expressed as:

$$
O D B_{\text {rawi }}=\sum_{j=1}^{p} \sum_{k=1}^{v} \sqrt{\left(x_{i j k}-c_{i k}\right)^{2}}
$$

where $p$ represents the total number of food items per species $i, v$ is the number of ordinated axes, $c_{i k}$ is the centroid for the $i$ th species on axis $k$, and $x_{i j k}$ is the position for the $j$ th food item used by the $i$ th species on the $k$ th axis. ${ }^{27}$

Significant differences between order- and family-level clades were determined using a phylogenetic ANOVA available through the aov.phylo function in geiger ${ }^{72}$ v. 2.0.7 and via a posthoc Tukey's (HSD) test $(\alpha=0.05)$. Lastly, we compared ODBs between these clades using a non-parametric Kolmogorov-Smirnov (K-S) test. 